\title{
Investigating Racial Disparities in Use of NK1 Receptor Antagonists to Prevent Chemotherapy-Induced Nausea and Vomiting Among Women with Breast Cancer
}

\author{
Devon K. Check ${ }^{1}$, Katherine E. Reeder-Hayes ${ }^{2,3}$, Ethan M. Basch ${ }^{1,2,3}$, Leah L. Zullig ${ }^{4,5}$, \\ Morris Weinberger ${ }^{1,4}$, and Stacie B. Dusetzina ${ }^{1,2,6}$ \\ ${ }^{1}$ Department of Health Policy and Management, Gillings School of Global Public Health, \\ University of North Carolina at Chapel Hill \\ ${ }^{2}$ Lineberger Comprehensive Cancer Center, University of North Carolina at Chapel Hill \\ ${ }^{3}$ Division of Hematology/Oncology, UNC School of Medicine, University of North Carolina at \\ Chapel Hill \\ ${ }^{4}$ Center for Health Services Research in Primary Care, Durham Veterans Affairs Medical Center, \\ Durham, NC \\ ${ }^{5}$ Division of General Internal Medicine, Department of Medicine, Duke University, Durham, NC \\ ${ }^{6}$ Division of Pharmaceutical Outcomes and Policy, UNC Eshelman School of Pharmacy, \\ University of North Carolina at Chapel Hill
}

\begin{abstract}
Purpose-Chemotherapy-induced nausea and vomiting (CINV) is a major concern for cancer patients and, if uncontrolled, can seriously compromise quality of life (QOL) and other treatment outcomes. Because of the expense of antiemetic medications used to prevent CINV (particularly oral medications filled through Medicare Part D), disparities in their use may exist.
\end{abstract}

Methods-We used 2006-2012 SEER-Medicare data to evaluate the use of neuroknin-1 receptor antagonists (NK1s), a potent class of antiemetics, among black and white women initiating highly emetogenic chemotherapy for the treatment of early-stage breast cancer. We used modified Poisson regression to assess the relationship between race and (1) any NK1 use, (2) oral NK1 (aprepitant) use, and (3) intravenous NK1 (fosaprepitant) use. We report adjusted risk ratios (aRR) and $95 \%$ confidence intervals $(\mathrm{CI})$.

Results-The study included 1,130 women. We observed racial disparities in use of any NK1 (aRR: $0.68,95 \%$ CI: $0.51-0.91$ ) and in use of oral aprepitant specifically (aRR: 0.54, 95\% CI: 0.35-0.83). We did not observe disparities in intravenous fosaprepitant use. After controlling for variables related to socioeconomic status, disparities in NK1 and aprepitant use were reduced but not eliminated.

Corresponding Author and Reprint Requests: Devon K. Check, University of North Carolina at Chapel Hill, Gillings School of Global Public Health, Department of Health Policy and Management, CB\#7411, Chapel Hill, NC 27599, dkcheck@ unc.edu, Phone: 610-613-7784.

Conflict of Interest: The authors declare that they have no conflict of interest. 
Conclusions-We found racial disparities in women's use of oral NK1s for the prevention of CINV. These disparities may be partly explained by racial differences in socioeconomic status, which may translate into differential ability to afford the medication.

\section{Keywords}

Supportive care; palliative care; health services research; racial disparities

\section{Introduction}

Patients initiating cancer treatment have consistently cited chemotherapy-induced nausea and vomiting (CINV) as a major and fearful concern.[1] Poorly-controlled CINV can have severe physiological consequences, including dehydration, nutritional derangements, metabolic imbalances, and anorexia.[2] Thus, inadequate CINV control can lead to deterioration of a patient's functional condition and quality of life (QOL). [3-5] Further, hospital admissions, emergency department (ED) visits, and outpatient hospital visits after the first cycle of chemotherapy are both common and costly, with one study estimating the cost of treating CINV between the first and second cycle at $\$ 5,299$ among patients with a visit, and $\$ 731$ across all patients receiving moderately or highly emetogenic chemotherapy. [6] In addition, uncontrolled CINV can lead to decreased chemotherapy adherence or even withdrawal from potentially beneficial chemotherapy.[2,7] CINV control is therefore a critical aspect of high-quality cancer care and has profound implications for patients' cancer care experience.

Oncology professional organizations produce and endorse clinical practice guidelines for the use of antiemetics to prevent CINV.[8-10] For several years, the guidelines have recommended prophylactic use of the most potent class of antiemetic, neurokinin-1 recetpor antagonists (NK1s), for patients receiving highly-emetogenic chemotherapy. Until 2008, aprepitant, an oral formulation, was the only NK1 available for CINV prophylaxis. Barriers to aprepitant use exist. First, in many cases, patients are required to fill a prescription for aprepitant at their home pharmacy, rather than receive it in the clinic at the time of their chemotherapy infusion. Second, the drug is expensive relative to other antiemetics, and patients may be subject to high cost sharing, particularly when the drug is filled at a pharmacy and reimbursed under Medicare Part D. Estimates suggest that three aprepitant capsules cost over $\$ 500$ under Medicare Part D, and patients may be responsible for 25 to 50 percent of that cost, depending on their phase of the Part D benefit (i.e., in the initial coverage phase or in the doughnut hole, respectively).[11]

Evidence suggests that cost and access barriers may disproportionately affect minority patients. Studies of patients with lung, prostate, and colorectal cancers have shown black race to be negatively associated with use of other antiemetic drugs.[12,13] Whether this finding extends to NK1s and to other cancers is unknown. Assessing the relationship between race and NK1 use among breast cancer patients is particularly important, as this population frequently receives highly emetogenic chemotherapy. As well, research has demonstrated that black breast cancer patients may be more likely than white patients to have gaps in, or discontinue use of, chemotherapy because of hospitalizations and acute 
illness [14] possibly due to adverse effects of treatment. In general, minority cancer patients are more likely than white patients to experience uncontrolled symptoms and to report inadequate supportive care for pain and psychosocial symptoms.[15-19] As a first step towards understanding how the quality of CINV prophylaxis may contribute to racial disparities in breast cancer care, we assessed potential racial disparities in prophylactic use of NK1s among early-stage breast cancer patients beginning a chemotherapy regimen for which use of an NK1 is guideline-recommended. We were also interested to learn whether disparities were attenuated by intravenous (versus oral) NK1 use.

\section{Methods}

\section{Data}

We used the National Cancer Institute's Surveillance Epidemiology and End Result (SEER) database linked with Medicare fee-for-service claims from 2006-2012. The SEER program consists of population-based cancer registries and represents $28 \%$ of the population with cancer. SEER data are merged with fee-for-service Medicare claims to allow for assessments of health services use among Medicare beneficiaries with cancer.[20] Our study was conducted in accordance with a SEER-Medicare data use agreement and was approved by the Institutional Review Board at the University of North Carolina at Chapel Hill.

\section{Sample}

We included women aged 65 years and older who were diagnosed with stage I, II, or III breast cancer between January 1, 2007 and December 31, 2011 (Figure 1). Eligible women were: (1) not diagnosed at autopsy or death; (2) continuously enrolled in Medicare Parts and A and B for 6 months before and 12 months after diagnosis; (3) continuously enrolled in Medicare Part D for 12 months after diagnosis; and (4) not enrolled in an HMO for 6 months before and 12 months after diagnosis. There were 27,160 women meeting these criteria. From this sample, we restricted our study to women who received surgery (mastectomy or breast conserving surgery) and initiated chemotherapy within 6 months of diagnosis $(n=4,651)$. The analysis was further restricted to women whose first cycle of adjuvant chemotherapy included an anthracycline and cyclophosphamide $(n=1,569)$, as guidelines have consistently recommended use of an NK1 for these regimens throughout the study period. $[9,21,22,8,10]$ Our sample was limited to women initiating adjuvant chemotherapy following surgery (versus women receiving neoadjuvant chemotherapy) in an effort to make the sample as homogenous as possible with regard to treatment experiences and potential unmeasured confounders. Because of the small proportion of non-black minorities $(n=118)$, the study was restricted to black and white women $(n=1,451)$. Finally, we restricted our sample to women who initiated chemotherapy on or after February 1, 2007, so that we could observe Part D prescription drug claims for antiemetics in the 30 days before chemotherapy initiation $(n=1,130)$.

\section{Variables}

Our primary outcome was patients' use of an NK1 during the first cycle of adjuvant chemotherapy. NK1 users were defined as having a Medicare Part D claim for aprepitant (oral formulation), as identified by the drug name, in the 30 days before or on the day of 
chemotherapy initiation. Alternatively, they had a Part B claim for aprepitant in the 30 days before or on the day of chemotherapy initiation, as identified using Health Care Common Procedure Coding System codes (J8501) and as recorded in the outpatient, physician services or durable medical equipment claims files. Finally, NK1 users could have a claim for fosaprepitant (IV formulation) (C9242, J1453) on the day of chemotherapy initiation, as recorded in the outpatient or physician services files.

Our main independent variable was race (black or white), as reported in the Patient Entitlement and Diagnosis Summary File. Covariates included patients' demographic and clinical characteristics: age, cancer stage, tumor grade, hormone receptor status, lymph node involvement, and comorbid illness (calculated using the Klabunde modification of the Charlson score based on patients' Medicare Part A and B claims pre-diagnosis).[23] We also measured marital status and receipt of a low-income subsidy to assist with prescription drug costs (i.e. Medicaid dual eligibility and/or "extra help" through the Medicare Part D program). Although patients dually eligible for Medicare and Medicaid receive subsidies to assist with drug co-pays, their prescription drugs are typically covered under Medicare Part $D$ versus Medicaid. Other measures of socioeconomic status (SES) included census tractlevel high school completion rate and median income, obtained from the 2000 census. Geographic variables were U.S. region of residence, and extent of urbanization at patients' residences.

\section{Statistical Analysis}

We compared the distributions of patient characteristics between racial groups using chisquared tests. To directly estimate relative risk with robust error variance, we used modified Poisson regression[24] to assess the relationship between race and NK1 use controlling for pre-specified patient characteristics. Because black women are disproportionately likely to receive drug copay assistance through Medicaid dual eligibility or a Part D low-income subsidy,[25,26] we included a drug copay assistance indicator and an interaction of race and copay assistance in our primary models to determine whether the models should be stratified by drug copay assistance receipt. Because the interaction effect was not statistically significant, we present the main effects models. Specifically, we present risks and adjusted risk ratios (aRR) with 95\% confidence intervals (CI) for NK1 use, comparing black and white women. We estimated separate models for any NK1 use, aprepitant use, and fosaprepitant use. Because fosaprepitant was not approved by the FDA until 2008, this model was limited to patients who initiated chemotherapy in 2009 or later $(\mathrm{N}=524)$.

Accounting for Socioeconomic Status-The Institute of Medicine (IOM) defines racial healthcare disparities as differences in treatment not justified by racial differences in health status or preferences. [27] Analytic approaches to implement this definition of disparities use statistical models that control only for differences in health status (e.g. comorbidity, age), clinical need (e.g., tumor characteristics) and, if available, preferences for care, between racial groups.[13,28,29] This approach recognizes the mediating role of an individual's SES and SES-related factors, as minorities tend to have lower SES profiles than whites, and such differences can impact care received. Therefore, the IOM's model does not adjust for SES-related factors, as doing so may reduce or eliminate the estimated 
independent effect of race on care and give a false picture of the care experience of vulnerable patients. In accordance with the IOM definition of health care disparities, our primary models adjusted for clinical characteristics, namely: age, year of chemotherapy initiation, tumor characteristics, and medical comorbidity.[29] In secondary analyses we assessed whether our findings would differ when including census tract-level SES, marital status, or geography in the primary model.

\section{Sensitivity Analyses}

In an exploratory model, we excluded tumor characteristics, since these factors should not influence a patient's need for antiemetics. Further, because advanced stage at diagnosis, $[30,31]$ hormone receptor negative phenotype, and high grade are more common in black women,[30,32] including these covariates might actually attenuate the effect of race on likelihood of receiving CINV prophylaxis. Results from these analyses were consistent with the primary analysis and are not shown.

\section{Results}

Among the 1,130 women who met our eligibility criteria, 1,015 (89.8\%) were white. Compared to white women, black women were less likely to be married (25\% versus 53\%) and more likely to receive drug copay assistance through Medicaid or Medicare Part D (70\% versus $21 \%$ ). There were also racial differences in census tract-level income and education and U.S. region of residence (see Table 1).

In the unadjusted analyses, we found statistically significant racial differences in women's use of any NK1 (41\% white vs. $28 \%$ black; $p<0.01)$ and aprepitant use $(29 \%$ white vs. $16 \%$ black, $\mathrm{p}<0.01)$, but not in fosaprepitant use $(15 \%$ white vs. $12 \%$ black, $\mathrm{p}=0.41)$. Unadjusted associations of each covariate with NK1, aprepitant, and fosaprepitant use are shown in Appendix Table 1.

In models adjusting for clinical characteristics only, racial disparities remained in use of any NK1 (aRR: 0.68, 95\% CI: 0.51-0.91) and aprepitant (aRR: 0.54, 95\% CI: 0.35-0.83). The relationship between race and fosaprepitant use was non-significant (aRR: 0.82, 95\% CI: 0.51-1.33) (see Table 2). Secondary models that included measures of SES (census tractlevel income and education and drug copay assistance receipt), marital status, and geographic factors were consistent with our primary models; however, estimates were no longer statistically significant. Being black reduced the risk of using any NK1 by $19 \%$ (aRR: 0.81, 95\%CI: 0.60-1.10; NS) and aprepitant by 32\% (aRR: 0.66 95\% CI: 0.43-1.104; NS)) (see Table 2).

\section{Discussion}

Among women initiating highly emetogenic chemotherapy containing an anthracycline and cyclophosphamide for their early-stage breast cancer, we observed that black women had a $32 \%$ decreased risk of using any NK1 for the prevention of CINV. When examining oral and intravenous NK1 formulations separately, black women had a 46\% decreased risk of receiving oral aprepitant. We did not observe a statistically significant racial difference in 
women's receipt of intravenous fosaprepitant. When we added SES- and geography-related variables to our models, the relationships between race and NK1 use and race and aprepitant, the effect estimates remained consistent with disparities, but were no longer statistically significant.

Despite clinical guidelines recommending the use of NK1s for anthracycline and cyclophosphamide-containing breast cancer regimens throughout the study period, only $40 \%$ of women in our sample used an NK1, according to our definition of prophylactic use. This may be due to a lack of provider familiarity with recommendations for NK1s for the chemotherapy regimens we examined, or institutional policies' failure to include NK1s in the antiemetic order sets for these chemotherapy regimens. Although guidelines have consistently recommended use of an NK1 for anthracycline- and cyclophosphamidecontaining breast cancer regimens throughout our study period, in earlier guidelines, these regimens were classified as "moderately" emetogenic; later in the study period, guideline updates reclassified the regimens as "highly" emetogenic.[8-10] This explanation is consistent with the substantial increase in NK1 use over time that we observed.

Our finding of a disparity is consistent with the limited research to date examining variation in use of antiemetics for CINV prevention. However, to our knowledge, our study is the first to include NK1s. In the only study to date that specifically investigated racial disparities in antiemetic use, Samuel et al. focused on patients with colorectal, prostate, and lung cancers in the Veterans Affairs system. Although they documented disparities in use of some antiemetics, their data were from the early 2000s, before NK1s were recommended by clinical guidelines for the prevention of CINV.[13] Gomez and colleagues explored patterns of guideline-concordant antiemetic use among lung cancer patients. Although not focused on disparities, the authors demonstrated racial and income differences in antiemetic use. However, this study was limited to a single state's cancer registry and did not include NK1s in the analysis.[12]

Our study is also the first of which we are aware to examine patterns of use of oral versus intravenous NK1s. It is important to distinguish between formulations because many patients are required to fill a prescription for oral aprepitant, a high-cost medication, at their home pharmacy. Under Medicare Part D, patients may be subject to high cost sharing. The introduction of intravenous fosaprepitant in 2008 may have helped obviate access and cost barriers related to use of oral therapy. Specifically, because fosaprepitant is administered in the clinic, it is covered under Medicare Part B. Although Part B tends to have 20\% coinsurance for all services, the large majority of Medicare beneficiaries have supplemental insurance coverage to assist with their out-of-pocket Part B costs.[33] Our identification of racial disparities in oral, but not intravenous, NK1 use supports the hypothesis that fosaprepitant is more affordable and accessible for patients. However, it is important to acknowledge that the lack of an observed disparity in fosaprepitant use could be due to insufficient sample size, as the fosaprepitant models were limited to patients who initiated chemotherapy in 2009 or later $(\mathrm{N}=524)$.

Two potential explanations for our observation of disparities in aprepitant use are that black women are: (1) equally as likely as white women to be prescribed aprepitant, but less likely 
to fill their prescriptions, possibly due to financial or other access barriers or (2) disproportionately likely to see providers who do not prescribe NK1s in accordance with clinical guidelines, because they are more likely to be treated in lower-performing settings. $[34,13]$ Both explanations seem plausible given our findings. Specifically, the fact that disparities in NK1 and aprepitant use were somewhat attenuated when SES-related factors were added to the models suggests that the disparities are at least partly explained by SES differences between black and white women. These SES differences could translate into differential ability to pay for prescription drugs, or differential access to high-quality care (including guideline-adherent antiemetic prescribing).[34,13] Interestingly, geographic region also appeared to partly attenuate disparities, suggesting a potential role for geographic variation in prescribing in explaining disparities in NK1 use.

Also of note, unlike prior reports, receipt of drug copay assistance appeared to act as an indicator of low income, rather than as an indicator of increased ability to pay for prescription drugs. Specifically, recent work by Neuner and Biggers documented a positive effect of drug copay assistance receipt on breast cancer patients' adherence to aromatase inhibitors.[35,25] In contrast, we observed a negative effect of drug copay assistance receipt on aprepitant use. One possible explanation for this difference may be our measure of drug copay assistance receipt, which combined assistance through Medicaid dual eligibility and the Part D low-income subsidy (i.e., a woman was said to be a drug copay assistance recipient if she received either type of assistance), whereas Neuner's and Biggers' studies measured only Part D low-subsidy receipt. Our results may reflect the mixed effect of dual eligibility status, which could be an indicator of decreased access, and Part D low-income subsidy receipt, which has been demonstrated to improve adherence.

Our study had several limitations. First, we focused on fee-for-service Medicare beneficiaries with Part D coverage. It is unknown whether our findings generalize to younger women, Medicare beneficiaries enrolled in an HMO or women without prescription drug coverage through Part D. Second, in our secondary models, we may have misclassified individuals' SES by using area-level measures of SES.[36,37] Third, because of the limited number of minority women represented in SEER-Medicare, we may have lacked statistical power for some comparisons. This is particularly true of the fosaprepitant models, which were limited to the 524 women who initiated chemotherapy in 2009 or later. Fourth, our use of Medicare administrative claims data for this analysis may have resulted in our undercapturing of NK1 use overall if these medications were provided in clinic and not billed to Medicare. However, we do not believe that capture issues would differentially affect black versus white patients, so comparisons between groups should be valid nonetheless. Fifth, with claims data, we could not separate physicians' failure to prescribe aprepitant from patients not filling prescriptions. Thus, although we have documented the existence of disparities, we are unable to identify the underlying causes of the observed disparities using SEER-Medicare data. Future studies should attempt to use clinical data to ascertain whether the disparities identified here reflect disparities in NK1 prescriptions or fills. If black and white women are equally likely to be prescribed NK1s but less likely to fill these prescriptions, disparities may in fact reflect barriers related to affordability and accessibility. 
Although our study and others have pointed to racial disparities in use of antiemetics to prevent CINV, it remains unclear whether such disparities contribute to the disparate outcomes of black and white cancer patients. In breast cancer, black-white disparities in systemic treatment adherence and survival have been documented. [38-40,14] Future studies should assess the role of treatment-induced side effect (including CINV) prevention and management in contributing to potential disparities not only in these observed outcomes but also in patients' quality of life and cancer care experience.

Our findings suggest that there may be a need for increased awareness among oncology providers of potential barriers to obtaining oral medications for CINV prevention. As well, our data point to several possible explanations for and points of intervention to reduce disparities. For example, disparities may stem from low income and minority patients' difficulty accessing or affording oral aprepitant, in which case the IV formulation may be more appropriate. Disparities may also stem from variation in prescribing, in which case provider-targeted interventions may help to reduce disparities. To inform specific solutions, further research is needed to determine the relative contribution of patient, provider, and system level factors to disparities.

\section{Supplementary Material}

Refer to Web version on PubMed Central for supplementary material.

\section{Acknowledgments}

This study used the linked SEER-Medicare database. The interpretation and reporting of these data are the sole responsibility of the authors. The database infrastructure used for this project was funded by the CER Strategic Initiative of UNC's Clinical \& Translational Science Award (UL1TR001111); and the UNC School of Medicine.

Funding: Acknowledgements: Ms. Check is supported by the National Cancer Institute under Award Number R25CA116339. Dr. Dusetzina is supported by National Institutes of Health Building Interdisciplinary Research Careers in Women's Health (BIRCWH) K12 Program and the North Carolina Translational and Clinical Sciences Institute (UL1TR001111). Drs. Weinberger and Zullig are supported by the Department of Veterans Affairs Office of Health Services Research and Development (Grant No. RCS 91-408 to MW and Grant No. CDA 13-025 to LLZ).

\section{References}

1. Hickok JT, Roscoe JA, Morrow GR, King DK, Atkins JN, Fitch TR. Nausea and emesis remain significant problems of chemotherapy despite prophylaxis with 5-hydroxytryptamine-3 antiemetics: a University of Rochester James P. Wilmot Cancer Center Community Clinical Oncology Program Study of 360 cancer patients treated in the community. Cancer. 2003; 97(11):2880-2886.10.1002/ cncr.11408 [PubMed: 12767103]

2. National Cancer Institute. [Accessed 18 Feb 2015] Nausea and Vomiting. 2014. http:// www.cancer.gov/cancertopics/pdq/supportivecare/nausea/HealthProfessional

3. Cohen L, de Moor CA, Eisenberg P, Ming EE, Hu H. Chemotherapy-induced nausea and vomiting: incidence and impact on patient quality of life at community oncology settings. Supportive care in cancer: official journal of the Multinational Association of Supportive Care in Cancer. 2007; 15(5): 497-503.10.1007/s00520-006-0173-z [PubMed: 17103197]

4. Bloechl-Daum B, Deuson RR, Mavros P, Hansen M, Herrstedt J. Delayed nausea and vomiting continue to reduce patients' quality of life after highly and moderately emetogenic chemotherapy despite antiemetic treatment. Journal of clinical oncology: official journal of the American Society of Clinical Oncology. 2006; 24(27):4472-4478.10.1200/JCO.2006.05.6382 [PubMed: 16983116] 
5. Glaus A, Knipping C, Morant R, Bohme C, Lebert B, Beldermann F, Glawogger B, Ortega PF, Husler A, Deuson R. Chemotherapy-induced nausea and vomiting in routine practice: a European perspective. Supportive care in cancer: official journal of the Multinational Association of Supportive Care in Cancer. 2004; 12(10):708-715.10.1007/s00520-004-0662-x [PubMed: 15278682]

6. Burke TA, Wisniewski T, Ernst FR. Resource utilization and costs associated with chemotherapyinduced nausea and vomiting (CINV) following highly or moderately emetogenic chemotherapy administered in the US outpatient hospital setting. Supportive care in cancer: official journal of the Multinational Association of Supportive Care in Cancer. 2011; 19(1):131-140.10.1007/ s00520-009-0797-x [PubMed: 20101417]

7. Langford P, Chrisp P. Fosaprepitant and aprepitant: an update of the evidence for their place in the prevention of chemotherapy-induced nausea and vomiting. Core evidence. 2010; 5:77-90. [PubMed: 21042544]

8. Basch E, Prestrud AA, Hesketh PJ, Kris MG, Feyer PC, Somerfield MR, Chesney M, Clark-Snow RA, Flaherty AM, Freundlich B, Morrow G, Rao KV, Schwartz RN, Lyman GH. American Society of Clinical O. Antiemetics: American Society of Clinical Oncology clinical practice guideline update. Journal of clinical oncology: official journal of the American Society of Clinical Oncology. 2011; 29(31):4189-4198.10.1200/JCO.2010.34.4614 [PubMed: 21947834]

9. Roila F, Herrstedt J, Aapro M, Gralla RJ, Einhorn LH, Ballatori E, Bria E, Clark-Snow RA, Espersen BT, Feyer P, Grunberg SM, Hesketh PJ, Jordan K, Kris MG, Maranzano E, Molassiotis A, Morrow G, Olver I, Rapoport BL, Rittenberg C, Saito M, Tonato M, Warr D, Group EMGW. Guideline update for MASCC and ESMO in the prevention of chemotherapy- and radiotherapyinduced nausea and vomiting: results of the Perugia consensus conference. Annals of oncology: official journal of the European Society for Medical Oncology/ESMO. 2010; 21(Suppl 5):v232243.10.1093/annonc/mdq194 [PubMed: 20555089]

10. National Comprehensive Cancer Network (NCCN). [Accessed 18 Feb 2015] Clinical Practice Guidelines in Oncology, Anti-emesis. Version 1.2012. http://www.medicine.wisc.edu/ williams/ anti-emesis.pdf

11. Center for Medicare and Medicaid Services. [Accessed October 7 2015] Medicare Plan Finder. https://http://www.medicare.gov/find-a-plan/questions/home.aspx

12. Gomez DR, Liao KP, Giordano S, Nguyen H, Smith BD, Elting LS. Adherence to national guidelines for antiemesis prophylaxis in patients undergoing chemotherapy for lung cancer: a population-based study. Cancer. 2013; 119(7):1428-1436.10.1002/cncr.27899 [PubMed: 23212885]

13. Samuel CA, Landrum MB, McNeil BJ, Bozeman SR, Williams CD, Keating NL. Racial disparities in cancer care in the Veterans Affairs health care system and the role of site of care. American journal of public health. 2014; 104(Suppl 4):S562-571.10.2105/AJPH.2014.302079 [PubMed: 25100422]

14. Griggs JJ, Sorbero ME, Stark AT, Heininger SE, Dick AW. Racial disparity in the dose and dose intensity of breast cancer adjuvant chemotherapy. Breast cancer research and treatment. 2003; 81(1):21-31.10.1023/A:1025481505537 [PubMed: 14531494]

15. John DA, Kawachi I, Lathan CS, Ayanian JZ. Disparities in perceived unmet need for supportive services among patients with lung cancer in the Cancer Care Outcomes Research and Surveillance Consortium. Cancer. 2014; 120(20):3178-3191.10.1002/cncr.28801 [PubMed: 24985538]

16. Reyes-Gibby CC, Anderson KO, Shete S, Bruera E, Yennurajalingam S. Early referral to supportive care specialists for symptom burden in lung cancer patients: a comparison of nonHispanic whites, Hispanics, and non-Hispanic blacks. Cancer. 2012; 118(3):856-863.10.1002/ cncr.26312 [PubMed: 21751190]

17. Martinez KA, Snyder CF, Malin JL, Dy SM. Is race/ethnicity related to the presence or severity of pain in colorectal and lung cancer? Journal of pain and symptom management. 2014; 48(6):1050 1059.10.1016/j.jpainsymman.2014.02.005 [PubMed: 24747225]

18. Fisch MJ, Lee JW, Weiss M, Wagner LI, Chang VT, Cella D, Manola JB, Minasian LM, McCaskill-Stevens W, Mendoza TR, Cleeland CS. Prospective, observational study of pain and analgesic prescribing in medical oncology outpatients with breast, colorectal, lung, or prostate 
cancer. Journal of clinical oncology: official journal of the American Society of Clinical Oncology. 2012; 30(16):1980-1988.10.1200/JCO.2011.39.2381 [PubMed: 22508819]

19. McNeill JA, Reynolds J, Ney ML. Unequal quality of cancer pain management: disparity in perceived control and proposed solutions. Oncology nursing forum. 2007; 34(6):11211128.10.1188/07.ONF.1121-1128 [PubMed: 18024339]

20. Warren JL, Klabunde CN, Schrag D, Bach PB, Riley GF. Overview of the SEER-Medicare data: content, research applications, and generalizability to the United States elderly population. Medical care. 2002; 40(8 Suppl):IV-3-18.10.1097/01.MLR.0000020942.47004.03

21. Roila F, Hesketh PJ, Herrstedt J. Antiemetic Subcommitte of the Multinational Association of Supportive Care in C. Prevention of chemotherapy- and radiotherapy-induced emesis: results of the 2004 Perugia International Antiemetic Consensus Conference. Annals of oncology: official journal of the European Society for Medical Oncology/ESMO. 2006; 17(1):20-28.10.1093/ annonc/mdj078 [PubMed: 16314401]

22. Kris MG, Hesketh PJ, Somerfield MR, Feyer P, Clark-Snow R, Koeller JM, Morrow GR, Chinnery LW, Chesney MJ, Gralla RJ, Grunberg SM. American Society of Clinical Oncology guideline for antiemetics in oncology: update 2006. Journal of clinical oncology: official journal of the American Society of Clinical Oncology. 2006; 24(18):2932-2947.10.1200/JCO.2006.06.9591 [PubMed: 16717289]

23. Klabunde CN, Potosky AL, Legler JM, Warren JL. Development of a comorbidity index using physician claims data. Journal of clinical epidemiology. 2000; 53(12):1258-1267. [PubMed: 11146273]

24. Zou G. A modified poisson regression approach to prospective studies with binary data. Am J Epidemiol. 2004; 159(7):702-706. [PubMed: 15033648]

25. Biggers A, Neuner Joan, Smith Elizabeth, Pezzin Liliana, Laud Purushottam, Charlson John A, Smallwood Alicia. Medicare Part D low-income subsidy and disparities in breast cancer treatment. J Clin Oncol. 2014; 32(suppl 30):abstrat 2.

26. Neuman P, Strollo MK, Guterman S, Rogers WH, Li A, Rodday AM, Safran DG. Medicare prescription drug benefit progress report: findings from a 2006 national survey of seniors. Health affairs. 2007; 26(5):w630-643.10.1377/hlthaff.26.5.w630 [PubMed: 17711865]

27. Institute of Medicine. Unequal Treatment: Confronting Racial and Ethnic Disparities in Health Care. Washington, D.C: 2002.

28. Le Cook B, McGuire TG, Lock K, Zaslavsky AM. Comparing methods of racial and ethnic disparities measurement across different settings of mental health care. Health services research. 2010; 45(3):825-847.10.1111/j.1475-6773.2010.01100.x [PubMed: 20337739]

29. McGuire TG, Alegria M, Cook BL, Wells KB, Zaslavsky AM. Implementing the Institute of Medicine definition of disparities: an application to mental health care. Health services research. 2006; 41(5):1979-2005.10.1111/j.1475-6773.2006.00583.x [PubMed: 16987312]

30. Joslyn SA, West MM. Racial differences in breast carcinoma survival. Cancer. 2000; 88(1):114 123. [PubMed: 10618613]

31. Clegg LX, Li FP, Hankey BF, Chu K, Edwards BK. Cancer survival among US whites and minorities: a SEER (Surveillance, Epidemiology, and End Results) Program population-based study. Archives of internal medicine. 2002; 162(17):1985-1993. [PubMed: 12230422]

32. Elledge RM, Clark GM, Chamness GC, Osborne CK. Tumor biologic factors and breast cancer prognosis among white, Hispanic, and black women in the United States. Journal of the National Cancer Institute. 1994; 86(9):705-712. [PubMed: 7908990]

33. Kaiser Family Foundation. [Accessed 03 March 2015] Medicare at a Glance. http://kff.org/ medicare/fact-sheet/medicare-at-a-glance-fact-sheet/

34. Jha AK, Orav EJ, Epstein AM. Low-quality, high-cost hospitals, mainly in South, care for sharply higher shares of elderly black, Hispanic, and medicaid patients. Health affairs. 2011; 30(10):19041911.10.1377/hlthaff.2011.0027 [PubMed: 21976334]

35. Neuner JM, Kamaraju S, Charlson JA, Wozniak EM, Smith EC, Biggers A, Smallwood AJ, Laud PW, Pezzin LE. The introduction of generic aromatase inhibitors and treatment adherence among Medicare D enrollees. Journal of the National Cancer Institute. 2015; 107(8)10.1093/jnci/djv130 
36. Sin DD, Svenson LW, Man SF. Do area-based markers of poverty accurately measure personal poverty? Canadian journal of public health = Revue canadienne de sante publique. 2001; 92(3): 184-187. [PubMed: 11496626]

37. Diez-Roux AV, Kiefe CI, Jacobs DR Jr, Haan M, Jackson SA, Nieto FJ, Paton CC, Schulz R. Area characteristics and individual-level socioeconomic position indicators in three population-based epidemiologic studies. Annals of epidemiology. 2001; 11(6):395-405. [PubMed: 11454499]

38. Hassett MJ, Griggs JJ. Disparities in breast cancer adjuvant chemotherapy: moving beyond yes or no. Journal of clinical oncology: official journal of the American Society of Clinical Oncology. 2009; 27(13):2120-2121.10.1200/JCO.2008.21.1532 [PubMed: 19307493]

39. Hershman D, Weinberg M, Rosner Z, Alexis K, Tiersten A, Grann VR, Troxel A, Neugut AI. Ethnic neutropenia and treatment delay in African American women undergoing chemotherapy for early-stage breast cancer. Journal of the National Cancer Institute. 2003; 95(20):1545-1548. [PubMed: 14559877]

40. Hershman DL, Unger JM, Barlow WE, Hutchins LF, Martino S, Osborne CK, Livingston RB, Albain KS. Treatment quality and outcomes of African American versus white breast cancer patients: retrospective analysis of Southwest Oncology studies S8814/S8897. Journal of clinical oncology: official journal of the American Society of Clinical Oncology. 2009; 27(13):21572162.10.1200/JCO.2008.19.1163 [PubMed: 19307504] 

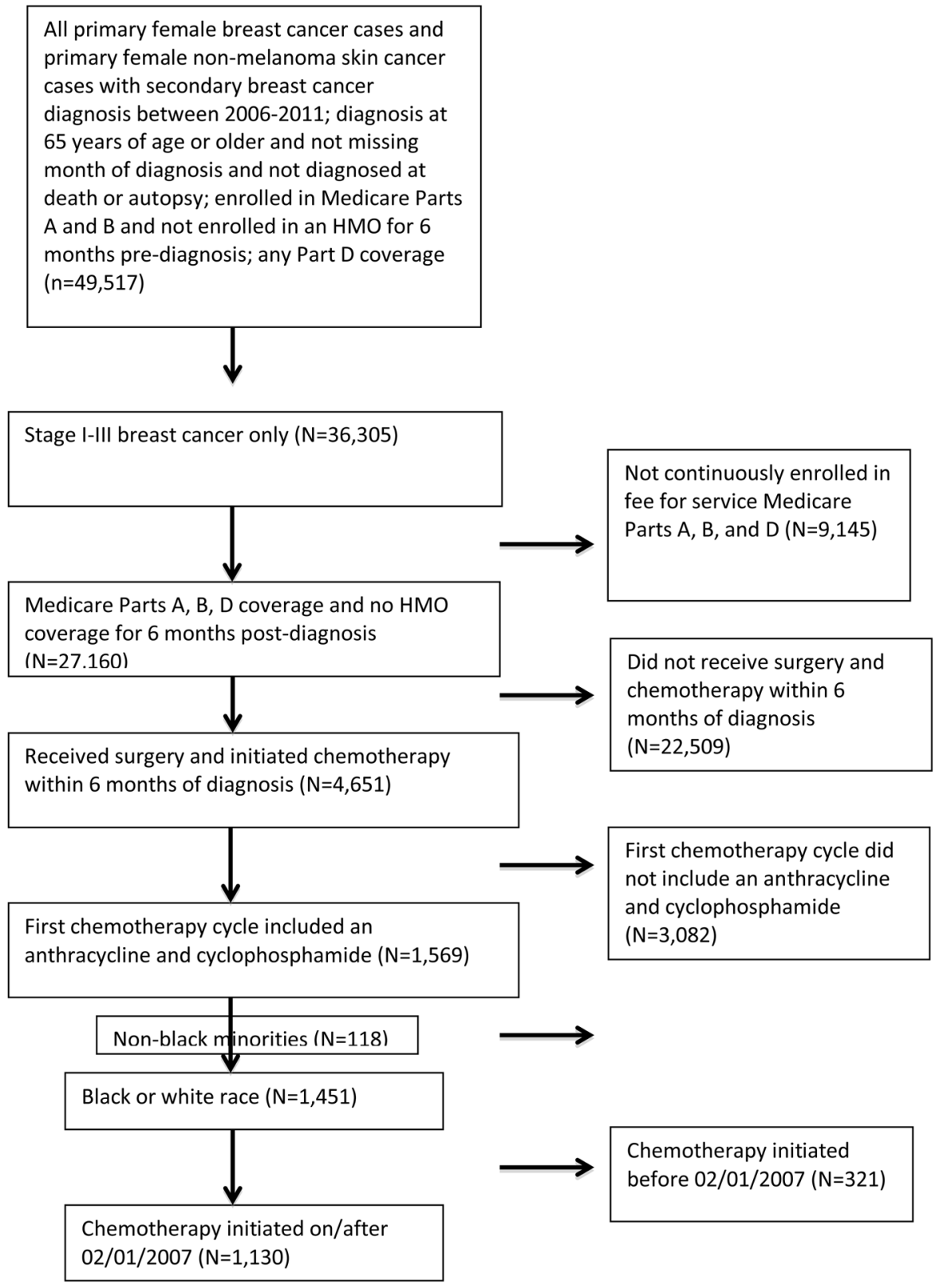

Figure 1.

CONSORT Diagram

Breast Cancer Res Treat. Author manuscript; available in PMC 2017 April 01. 


\section{Table 1}

Sample Characteristics, by Race

\begin{tabular}{|c|c|c|c|}
\hline & White & $\underline{\text { Black }}$ & p-value \\
\hline Number of Patients & 1,015 & 115 & \\
\hline \multicolumn{4}{|l|}{ Demographic Characteristics } \\
\hline \multicolumn{4}{|l|}{ Age at Cancer Diagnosis } \\
\hline $65-66$ & 20.7 & 25.2 & 0.7 \\
\hline $67-68$ & 24.7 & 24.4 & \\
\hline $69-71$ & 25.1 & 22.6 & \\
\hline $72-91$ & 29.4 & 27.8 & \\
\hline \multicolumn{4}{|l|}{ Marital Status at Diagnosis ${ }^{a}$} \\
\hline Married/Partnered & 52.9 & 25.2 & $<0.0001$ \\
\hline Non Married/Partnered & 42.5 & -- & \\
\hline Unknown & 4.6 & -- & \\
\hline \multicolumn{4}{|c|}{ Median Household Income in Census Tract of Residence ${ }^{a}$} \\
\hline Quartile 1: $\$ 0-32,791$ & 21.6 & 53.0 & $<0.0001$ \\
\hline Quartile 2: $\$ 32,972-44,039$ & 25.5 & -- & \\
\hline Quartile 3: $\$ 44,040-58,436$ & -- & 13.0 & \\
\hline Quartile 4: \$58,437-188,340 & 27.1 & -- & \\
\hline Unknown & -- & 0 & \\
\hline \multicolumn{4}{|c|}{ Proportion of Adult Residents with No High School Degree in Census Tract of Residence ${ }^{a}$} \\
\hline Quartile 1: 1.22-9.69\% & 27.4 & -- & $<0.0001$ \\
\hline Quartile 2: 9.70-16.57\% & 26.7 & -- & \\
\hline Quartile 3: $16.58-27.88 \%$ & -- & 30.4 & \\
\hline Quartile 4: $27.89-75.17 \%$ & 20.3 & 57.4 & \\
\hline Unknown & -- & 0 & \\
\hline \multicolumn{4}{|c|}{ Drug Copay Assistance (Medicaid Dual Eligibility and/or Part D Low Income Subsidy) } \\
\hline Yes & 21.1 & 69.6 & $<0.0001$ \\
\hline No & 78.9 & 30.4 & \\
\hline \multicolumn{4}{|l|}{ Residence } \\
\hline Metropolitan County & 74.8 & 82.6 & 0.06 \\
\hline Non-Metropolitan County & 25.1 & 16.4 & \\
\hline \multicolumn{4}{|l|}{ U.S. Region } \\
\hline Northeast & 19.4 & 20.0 & $<0.0001$ \\
\hline Midwest & 18.0 & 14.8 & \\
\hline West & 37.4 & 14.8 & \\
\hline South & 25.1 & 50.4 & \\
\hline \multicolumn{4}{|l|}{ Clinical Characteristics } \\
\hline \multicolumn{4}{|l|}{ Year of Chemotherapy Initiation ${ }^{a, c}$} \\
\hline 2007 & 28.9 & 31.3 & 0.9 \\
\hline 2008 & 20.1 & 20.9 & \\
\hline 2009 & 17.0 & 18.3 & \\
\hline
\end{tabular}




\begin{tabular}{|c|c|c|c|}
\hline & White & Black & p-value \\
\hline 2010 & 14.8 & 11.3 & \\
\hline 2011 & 15.4 & 14.8 & \\
\hline 2012 & 3.8 & -- & \\
\hline \multicolumn{4}{|c|}{ Charlson Comorbidity Score } \\
\hline 0 & 78.4 & 75.7 & 0.2 \\
\hline 1 & 17.2 & 16.5 & \\
\hline$>1$ & 4.3 & -- & \\
\hline \multicolumn{4}{|l|}{ Cancer Stage } \\
\hline Stage I & 12.8 & 10.4 & 0.7 \\
\hline Stage II & 53.6 & 56.5 & \\
\hline Stage III & 33.6 & 33.0 & \\
\hline \multicolumn{4}{|c|}{ Hormone Receptor Status ${ }^{a}$} \\
\hline HR positive & 67.0 & 62.6 & 0.5 \\
\hline HR negative & 28.7 & -- & \\
\hline Unknown & 3.7 & -- & \\
\hline \multicolumn{4}{|l|}{ Tumor Grade ${ }^{a}$} \\
\hline Low & 10.3 & -- & 0.3 \\
\hline Intermediate & 40.1 & 33.9 & \\
\hline High & 45.9 & 56.5 & \\
\hline Unknown & 4.3 & -- & \\
\hline \multicolumn{4}{|c|}{ Lymph Node Involvement } \\
\hline Yes & 70.9 & 67.0 & 0.06 \\
\hline No & 27.7 & -- & \\
\hline Uknown & 1.4 & -- & \\
\hline
\end{tabular}

${ }^{a}$ Cell sizes including proportions reflecting Ns $<11$ or information that would allow $\mathrm{Ns}<11$ to be derived were suppressed (--) to protect patients' identities.

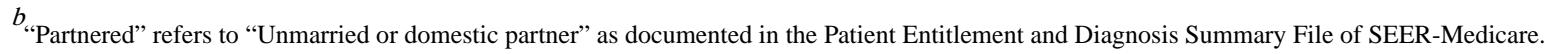

${ }^{c}$ A small proportion of patients initiated chemotherapy in 2012 because we only have SEER data on patients diagnosed through December 2011. Thus, only patients who received chemotherapy within the first 6 months of 2012 are included in our sample. 


\section{Table 2}

Adjusted Risks and Risk Ratios of Any NK1 Use, Aprepitant Use, and Fosaprepitant Use

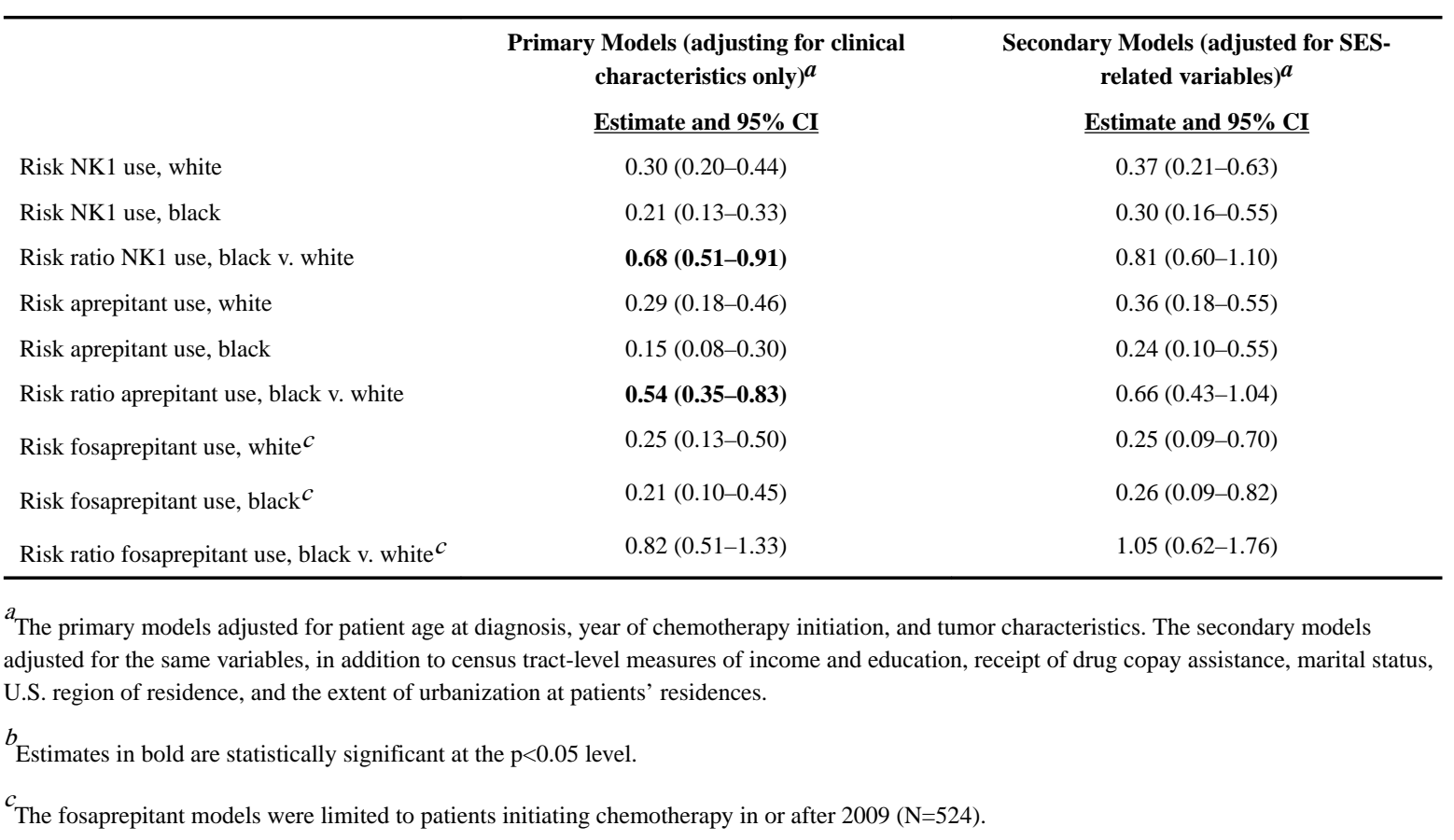

